\title{
Knowledge Management Practices for Improvement of Brazilian Hospital Websites
}

\author{
Kleber Cavalcante de Sousa, Jamil Ramsi Farkat Diógenes, Hélio Roberto Hékis, \\ Ricardo Alexsandro de Medeiros Valentim, Idelmarcia Dantas de Oliveira, Benilton Medeiros Nunes
} UFRN, Natal/RN, Brasil

\begin{abstract}
This work aims to verify how the Web portals of Universities Hospital located in the northeast of Brazil are contributing to the expansion of knowledge of its users from the analysis of interactive features associated with the three mechanisms of knowledge management: knowledge access (KA), knowledge creation (KC), and knowledge transfer (KT). The study is exploratory, descriptive, and qualitative type, such as a survey, developed through an adaptation of a relevant research, which involves the standardization of data collection instruments (questionnaires and interviews) applied directly to persons of a specific population, to assess knowledge management tools present in the University Hospital portals in the northeast region of Brazil. The results indicated that the resources from knowledge access were more prevalent than the others, ratifying the results found in research developed in Asian and North American Hospital portals.
\end{abstract}

Keywords: hospital portals, knowledge management, knowledge access (KA), knowledge creation (KC), knowledge transfer (KT)

\section{Introduction}

From knowledge management, it is possible to check how the hospital portals are contributing to the expansion of knowledge of its users.

Noting that context, the following question arises: Which interactive features the University of northeast region have portals to facilitate knowledge management and collaboration between hospitals and users?

In this context, this study aims to evaluate the interactive features of the portals of the University hospitals in the northeast region of Brazil, seeking to facilitate knowledge management and collaboration between hospitals and users, based on the three mechanisms of knowledge management: knowledge access (KA), knowledge creation (KC), and knowledge transference (KT).

Kleber Cavalcante de Sousa, M.Sc. Student in Production Engineering, Production Engineering Department, UFRN. Jamil Ramsi Farkat Diogenes, MS.c. Student in Production Engineering, Production Engineering Department, UFRN. Hélio Roberto Hékis, Ph.D. in Production Engineering, Professor of Production Engineering Department, UFRN.

Ricardo Alexsandro de Medeiros Valentim, Ph.D. in Electrical Engineering, Professor of Biomedical Engineering Department, UFRN.

Idelmarcia Dantas de Oliveira, M.Sc. in Production Engineering, Department of Distance Education, UFRN.

Benilton Medeiros Nunes, M.Sc. Student in Production Engineering, Production Engineering Department, UFRN.

Correspondence concerning this article should be addressed to Kleber Cavalcante de Sousa, Production Engineering Department, UFRN, Brazil. E-mail: kcsnat@gmail.com. 
Thus, the proposed assessment will identify the strengths and weaknesses of the sites studied, and comparison of the results obtained in this study with the research presented by Lee, Goh, and Chua (2007), in which he applied similar methodology to assess hospital and North Asian American portals.

The work will have the following structure: The first section deals with the introduction, the second, third, and fourth section present the theoretical foundation. The fifth section demonstrates the methodological procedures used, the sixth section deals with the description and analysis of the results, the seventh section will bring the conclusions.

\section{KA}

With the technological advancement supported in Internet dissemination, companies use the KA engine not only as a new way to create knowledge, but also as an opportunity to improve their ability to use and knowledge management (Siau, 2000).

Accessing the "World Wide Web" network becomes possible to raise marketing information involving customers and suppliers, as well as information on manufacturing operations, generation, and managerial processes.

$\mathrm{KA}$, in this context, corresponds to mechanism through which users access a website and its information. To analyze hospital portals, focus of this study, it is possible to raise its accessibility from the search tools. You can also identify the relevance in that these portals are using as basic point to sort the access volume (Lee et al., 2007).

It is possible to examine the ease of locating and accessing the portal, as are made queries (noting if there is a tool for this), the ease of finding what you are looking for on the page, as is the navigation and which tools to access. Another consideration to make is if the user can customize the information, or your organization customize it, if there are tools to facilitate access to the portal, if people are able to navigate the portal content easily and if the information of the organization is provided in the complete form (Tilly, 2006; Lee et al., 2007).

However, in the case of KA, it involves themes of action, identity, and freedom in three different aspects. Firstly, the production and distribution of knowledge depend on informed that agents can book the knowledge to their own advantage. Secondly, the control over the knowledge is organized around identity, defining borders that divide, on the one hand, those who have rights to this knowledge and, on the other hand, those who need it. Thirdly, the overcoming of the barriers between the beneficiaries and the victims of unequal access (Quinn, Baruch, \& Zien, 1997; Zhang \& Zhao, 2006).

Therefore, it is possible to say that KA is to provide information, preferably society that the individual considers useful, easily, and objectively. In the case of hospital portals, it turns out that with this knowledge can be more organized, the return of faster information can create new organizational ideas, online sharing, customization of some services, among other advantages, being useful to society.

\section{KC}

The convergence between the tacit and explicit knowledge can occur in four different ways: by socialization (tacitus $\times$ tacitus), by outsourcing (tacitus $\times$ explicit), by combining (explicit $\times$ explicit), or by internalization (explicit $\times$ tacitus). In outsourcing, the tacit knowledge into explicit as its content, once internalized, can be transmitted, shared, in a documentary format, allowing the understanding of other people. Already the internalization occurs when the amplification of an explicit knowledge results in a new tacit knowledge (Nonaka 
\& Takeuchi, 1997; Thomke \& Reinertsen, 1998; Saito, 2013). As regards hospital portals, object of study of this work, the KC in their corporate digital environments presents itself from the outsourcing of knowledge, when the institution's documents, administrative, and/or bureaucratic are provided and made available to the visiting public, which in turn has the opportunity to internalize the information obtained about the institution.

\section{KT}

KT refers to the mechanism through which knowledge is transferred or shared between the organization and the users and between the users themselves having as goal the development of knowledge through appropriate training and culture, enabling the correct interpretation of the information received (Lee et al., 2007).

It requires people to learn to use properly all the theoretical knowledge available to them, taking into account the specific conditions of the company. So the KT can be understood as replications of organizational routines and the knowledge is transmitted in a manner consistent with cumulative effect (Szulanski, 2000).

Sveiby (1998, p. 49) affirmed "The meaning that a person expresses never is the same as that raised in the mind of the person who receives it”. It can also occur that the issuer itself has difficulties in translating into words the knowledge you want to share with others, and even that does not have adequate words to that.

According to Szulanski (2000), knowledge sharing depends on the absorption capacity of the recipient, which is related to the previous knowledge and skills and the motivation that has to seek and accept different or new knowledge. The lack of motivation in this regard may lead to attitudes of procrastination, rejection, sabotage, passivity, acceptance in the implementation, and use of shared knowledge.

According to Dyer and Harbir (1998, p. 662), the human develops co-specialization as "partners in an alliance develop experience working together and accumulate information, language, and specialized know-how". This allows them to communicate efficiently and effectively, reducing errors and improving communication so quickly and increasing speed to market.

\section{Research Method}

The research is exploratory, descriptive, and qualitative, ranking it with a survey. As well, survey technique involves the standardization of data collection instruments (questionnaires and interviews) that are applied directly to the people of a specific population, whose behavior and characteristics they wish to know. It is suitable for testing hypotheses, models, and theory based propositions (Forza, 2002).

This study was conducted with a sample of 11 hospital units that correspond to $100 \%$ of the Federal University hospitals located in northeastern Brazil that are registered to the Brazilian Association of University Hospitals and Teaching (ABRAHUE). These units are shown in Table 1.

Although these studies have been limited to the very gates of University Hospitals in the northeast region of Brazil, it is believed that the results are applicable to any other portals, contributing to facilitate the collection, organization and dissemination of information and knowledge resources.

The survey took place in two steps. The first step matched the bibliographical research, in which it was necessary to review the existing literature and define the scope for the search, creating products such as the theoretical foundation and identification of the assumption of the research. The second exploratory phase and the delimitation of the survey, in which it was necessary to adapt the instrument collection and make your application through access to hospital and portals later run the treatment of information, enabling the analysis of the results and the dissertation of final thoughts. 
The collection instrument used was an adaptation of the same instrument applied by Lee et al. (2007). The adjustment performed was planned in order to emphasize the assessment of the portals in the three mechanisms used in knowledge management that are access, creation, and transfer of knowledge.

In the implementation phase the instrument of collection is understood as a checklist, in which guided the researchers to check the existence or not of the functionality contained through individualized access to portals. The features included in the collection are linked to instrument three mechanisms studied, as shown in Table 2.

Table 1

Hospital Portals Addressed by Research

\begin{tabular}{|l|l|l|l|}
\hline University Hospital & Federal State & Vinculated Institution & Website \\
\hline Professor Alberto Antunes & Alagoas & Federal University of Alagoas & http://www.hupaaufal.org \\
\hline Professor Edgard Santos & Bahia & Federal University of Bahia & http://www.complexohupes.ufba.br \\
\hline $\begin{array}{l}\text { Maternity Hospital Climério de } \\
\text { Oliveira }\end{array}$ & Bahia & Federal University of Bahia & http://www.mco.ufba.br \\
\hline $\begin{array}{l}\text { Maternity Hospital Assis } \\
\text { Chateaubriand }\end{array}$ & Ceará & Federal University of Ceará & http://www.meac.ufc.br/ \\
\hline Walter Cantídio & Ceará & Federal University of Ceará & http://www.huwc.ufc.br \\
\hline $\begin{array}{l}\text { Univesity Hospital of Federal } \\
\text { University of Maranhão }\end{array}$ & Maranhão & Federal University of Maranhão & http://www.huufma.br/site \\
\hline Univesity Hospital Lauro Wanderley & Paraiba & Federal University of Paraiba & http://www.hulw.ufpb.br \\
\hline Univesity Hospital Alcides Carneiro & Paraiba & $\begin{array}{l}\text { Federal University of Campinal http://www.ufcg.edu.br/prt_ufcg/or } \\
\text { Grande } \\
\text { gaos_suplementares/hu/hu.php }\end{array}$ \\
\hline Clinics Hospital & Pernambuco & Federal University of Pernambuco & http://www.ufpe.br/hc \\
\hline Univesity Hospital Ana Bezerra & $\begin{array}{l}\text { Rio Grande do } \\
\text { Norte }\end{array}$ & $\begin{array}{l}\text { Federal University of Rio Grande do } \\
\text { Norte }\end{array}$ & http://www.huab.ufrn.br \\
\hline $\begin{array}{l}\text { Univesity Hospital of Federal } \\
\text { University of Sergipe }\end{array}$ & Sergipe & Federal University of Sergipe & http://hospital.ufs.br \\
\hline
\end{tabular}

Table 2

Features Analyzed in Portals

$\mathrm{KA}, \mathrm{KC}$, and KT

(KA) Access: Easy to find and access to (KA) Query: Is there a facility to consult (KA) Results: Is there ease in finding what the portal? and there is tool for this purpose? is wanted?

(KA) Navigation: Is there ease in (KA) Personalized information: Can the (KA) Customized information: Does your navigation and use of the tools available? user customize the information? organization customize the information?

(KA) Accessibility: Are there tools to (KA) Accessibility: Can people have (KA) Presentation of information: Is the facilitate access to the portal? information provided on the portal in order complete?

\begin{tabular}{|l|l|l}
\hline $\mathrm{KC})$ Is there creation of knowledge? & $(\mathrm{KC})$ Is there user information acquisition? (KC) Is there data domain Acquisition?
\end{tabular}

\begin{tabular}{|ll|l|l}
\hline $\mathrm{KT})$ & Is there collaboration with the & (KT) Is there collaboration among users? & (KT) Is there synchronized support?
\end{tabular} Organization?

(KT) Are there information alerts?

(KT) Is there support to the users?

\section{Results}

When reviewing the evaluations of hospital portals, based on the checklist adopted, this study identified that all university hospitals in the northeast region of Brazil, use at least two mechanisms of knowledge management tools, between KA, KC, and mechanisms of KT.

The study showed that only two among the 11 selected portals use a combination of integrated knowledge management mechanisms (KA), (KC), and (KT). The study identified yet, results for each of the dimensions 
relating to knowledge management. So to facilitate the understanding, the presentation of the results will be made according to each dimension of knowledge.

\section{KA}

It was observed that all portals are accessible from the search tools, facilitating the navigation of any user, being found in the areas of Federal universities portals, whose hospitals portals are linked (except the University Hospital Professor Alberto Antunes), when you use the search term research sites, "Federal Hospitals", or even the name of the institution. These data and more about "KA" mechanism can be seen in Table 3.

Table 3

Number of Holder Portals Functionality Described in the Mechanism "KA"

\begin{tabular}{lcc}
\hline KA & Number of portals & $\%$ \\
\hline Easily locate and access to the portal & 11 & 100 \\
Easy to consult & 7 & 63.7 \\
Easy to find what you are looking for & 7 & 63.7 \\
Easy to navigate & 7 & 63.7 \\
Information personalization for users & 1 & 9 \\
Information customization for users & 8 & 72.7 \\
Are there tools to facilitate the accessibility to the portal? & 0 & 0 \\
Easy access to the portal content & 5 & 45.4 \\
Organization information is provided on the portal & 9 & 81.8 \\
\hline
\end{tabular}

Searching on query results, navigation, and accessibility, it was observed that most easily find information pages, plus links, tabbed query feature accessible, with the exception of the portals of the University Hospital Professor Edgard Santos, University Hospital Professor Lauro Wanderley, University Hospital Ana Bezerra, and University Hospital Professor Alcides Castro, that provide the information, however, the advanced query tool such as to expand or modify and search results are not available.

Personalization and customization, in only four portals: Maternity Hospital Climério de Oliveira, Hospital of Federal University of Sergipe, Walter Cantídio—Federal University of Ceará, and University Hospital of Federal University of Maranhão, allow the user to give opinion, expose ideas, change font size, thus, allow customizing the information, in addition to providing customized information by the organization. The other seven, did not identify themselves possibility for the user to customize the information gained. Already on the customization by the institutions, the portal serves as well in this regard.

In presenting the information, in all hospitals information portals are supplied complete, location, telephones, mission, and vision, among other information.

KC

Evaluating the KC that visitors get to access the portals studied, was identified in 11 portals. It is generated through some news on hospitals, and especially on health, with the exhibition of projects and campaigns.

The study pointed out that only $54.5 \%$ of websites assessed there is user information acquisition, that is, in six portals the organization acquires information from users, and in only three, there is data acquisition of the IP domain, that identifies the user. These data can be seen in Table 4 . 
Table 4

Number of Holder Portals Functionality Described in the Mechanism "KC"

\begin{tabular}{lll}
\hline KC & Number of portals & $\%$ \\
\hline Is there KC? & 11 & 100 \\
Is there information acquisition of the user? & 6 & 54.5 \\
Is there acquisition of the domain data? & 3 & 27.3 \\
\hline
\end{tabular}

In most hospital portals there are no tools that allow the creation of knowledge, on the part of the organization from the data and information collected from its users, although there is $\mathrm{KC}$ in these portals. Most portals are available to contact us with tool, for users to keep in touch by providing your opinion, contributing with their criticisms and suggestions. In these cases the $\mathrm{KC}$ is limited to what the visitor purchases, i.e., which is dedicated to information about the structuring of the hospital, history and services offered, results, and institutional data.

Notice that in the tabs of the Maternity Hospital Climério de Oliveira and University Hospital Professor Alberto Antunes, the KC is complemented through the Ombudsman's Office and the contact forms possible users to interact and share information, regarding their opinions, criticisms, and suggestions about the hospital, services, including on the portal.

In some portals there is the Ombudsman Service, where there is a form for users to communicate with each other, as in the case of the portal of the Clinics Hospital of Federal University of Pernambuco, the KC that the visitor buys are some news about the hospital, and, mainly, on health, with the exhibition of projects and scientific productions.

Already the portals of the Maternity Hospital Climério de Oliveira and the University Hospital Professor Alberto Antunes, from Federal University of Alagoas offer opportunities to have interaction with users and between them, since they have the contacts and timetables of the Ombudsman, providing innovative and interesting ways for the users stay in touch with all portals users.

In it, the visitor has the possibility to share information based on his experience at the hospital. He can praise a procedure, as well as criticize him. In the field, however, is the disclosure only of praise. The most recent dated in 2011, which could denote two situations: Either the information management is flawed by portal administrators, or their use is very scarce, to the point that no one wants to testify throughout the 1st semester of 2012. With respect to the acquisition of knowledge of user information, at which point they receive information, treat and improve the process of the portal of the University Hospital Professor Alberto Antunes, from Federal University of Alagoas, that identifies and reports on how many visitors are online, but does not inform how many have visited the website. That is, most portals acquire data from the user's domain, or tell you how many visitors are online at the time.

Some websites offer users to monitor and interact with the service and communication with other users about the news from the hospital via social networks, as is the case of the Maternity Hospital Assis Chateubraind.

\section{KT}

In the present study it was observed that all portals have superficial and limited KT tools. This transfer happens in particular the organization for users, because of the variety of information offered to visitors, which through these can take note and take its decisions.

The study pointed out that only $18.1 \%$ of hospitals surveyed providing that there are tools that provide the 
collaboration between users and the organization. Not being identified tools that provide the collaboration among road users, either synchronized, or even support for users that require guidance or help, to use the portal (see Table 5).

Table 5

Number of Holder Portals Functionality Described in the Mechanism "KT"

\begin{tabular}{lll}
\hline KT & Number of portals & $\%$ \\
\hline Is there collaboration between the users and the organization? & 2 & 18.1 \\
Is there collaboration among the users? & 0 & 0 \\
Is there synchronized support? & 0 & 0 \\
Does the portal present information alert? & 0 & 0 \\
Does the portal present support to the users? & 0 & 0 \\
\hline
\end{tabular}

It is important to highlight that the portals is not realized studied mechanisms to facilitate and stimulate the collaboration for the organization, except, Portal of The Clinics Hospital, from Federal University of Pernambuco and the Portal of Maternity Hospital Climério de Oliveira of Federal University of Bahia, the latter with a very interesting mechanism which allows users to post testimonials about their experiences during your stay, and or about the services that were provided by the hospital.

In the other portals, we were found that there are not mechanisms for integration between users, such as forums, or sites for testimonials.

The vast majority of portals as integration tool with users just contact tool or contact us via a form for the user to send email. This tool only supports the organization receive any user information, which may or may not produce some knowledge through this transfer, but that does not make possible to be no interaction among users. In the other portals was not seen mechanisms or tools to support users of the portals, if need, either, to alert them about issues and topics of interest that can be published in portals.

KT has been the subject of various approaches. This article-focused KT is the portal for the user and the user's portal. Although limited, this notion captures many of the elements that they focus the production of knowledge and its application.

\section{Conclusions}

Important to highlight that in the portals is not realized studied mechanisms to facilitate and stimulate the collaboration for the organization, except, Portal of The Clinics Hospital, from Federal University of Pernambuco, and the Portal of Maternity Hospital Climério de Oliveira of Federal University of Bahia, the latter with a very interesting mechanism which allows users to post testimonials about their experiences during your stay, and or about the services that were provided by the hospital.

In the other portals were not found there are mechanisms for integration between users, such as forums, or sites for testimonials.

The vast majority of portals as integration tool with users just contact tool or contact us via a form for the user to send email. This tool supports only the organization receive any user information, which may or may not produce some knowledge through this transfer, but that does not make possible to be no interaction between users.

Managing knowledge is an important strategy to achieve this increased competitiveness due to the better use of knowledge, which provides the highest productivity of people and processes, through better optimization of 
knowledge, using tools that facilitate the acquisition, creation and sharing of knowledge, which is characterized as the focus of the work.

Thus, this study evaluated the interactive features of the portals of the University hospitals in the northeast region of Brazil, identifying knowledge management mechanisms used and proving that the hospital contributes to enlarging portals of knowledge of users and organizations, and further that the interactive features of the northeast University portals facilitate knowledge management and collaboration between hospitals and users.

In this sense, it is concluded that the hospital searched portals, like Lee et al. (2007) shows in your research, offer many different information resources for its users. As for the tools of access to knowledge, the portals have search tools, access tabs to pages, information on the hospital, but few can customize or customize the information. This demonstrates that the mechanism of KA was more prevalent of the mechanisms KC and KT, coinciding with the study conducted with hospital portals in Asia and North America.

The most frequently identified the mechanism of KA points out that it is necessary, so that health professionals can convert your health care information in health knowledge, for visitors access through using of portal technology. This action is considered an important challenge for the managers of hospital organizations, regarding the issue of knowledge management.

With respect to the KC, most portals do not have tools available so that users can contribute to the KC. The only way available in the portals on which approaches the ideal for integrating users with health professionals, was the link "talk with us", with a simple message form. What is totally bound to perform the KC function.

The characteristics most commonly available to support KT engine are through the sharing of resources in terms of providing catalog information, external links to other websites and information visualization contributed by other users. Surprisingly, we found that support for the mechanism of KT, through online collaboration among users and among those still missing in many portals.

Secondly, there are currently many portals that also provide health information, but they are not operated by hospitals.

Thus, a future work can look for evaluation of these portals and examine the differences between them and the very gates of the hospital in terms of access, creation, and transfer of health information and knowledge.

Thus, the need for expansion of access to knowledge, tools such as search, advanced search, personalization and customization, so that users can have more access to knowledge.

Already with regard to the creation of knowledge, it would be interesting to have tools on portals that enable users to bring the information to allow the KC on the part of the hospital, through greater interaction.

Would be ideal if the hospital portals provide information such as: waiting time, rooms availability, drugs availability, doctors availability (by specialty), and other specific information on which help the user in choosing which hospital to go.

\section{References}

Associação Brasileira de Hospitais Universitários e de Ensino (ABRAHUE). (2012). Associated hospitals (Hospitais associados). Retrieved from http://www.abrahue.org.br/

Dyer, J. H., \& Harbir, S. (1998). The relational view: Cooperative strategy and sources of interorganizational competitive advantage. Academy of Management Review, 23(4), 660-679.

Forza, C. (2002). Survey research in operations management: A process-based perspective. International Journal of Operations and Production Management, 22(2), 152-194. 
Lee, C. S., Goh, D., \& Chua, A. (2007). Evaluation of hospital portals using knowledge management mechanisms. Proceedings of the 10th International Conference on Asian Digital Libraries ICADL, Hanoi, Vietnam.

Nonaka, I., \& Takeuchi, H. (1997). The knowledge-creating in company (Criação de conhecimento na empresa) (5rd ed.). Rio de Janeiro: Campus.

Quinn, J. B., Baruch, J. J., \& Zien, K. A. (1997). Innovation explosion: Using intellect and software to revolutionize growth strategies. New York: Free Press.

Saito, A. A. (2013). Importance of knowledge management (Importância da gestão do conhecimento). Retrieved from http://www1.folha.uol.com.br/poder/1008084-em-meio-a-crise-mundial-agencia-sp-eleva-nota-de-credito-do-brasil.shtml

Siau, K. (2000). Knowledge discovery as an aid to organizational creativity. Journal of Creative Behavior, 34(4), 248-258.

Sveiby, K. E. (1998). The new wealth of organizations-Generating and evaluating knowledge assets (A Nova Riqueza das Organizações-gerando e avaliando patrimônios de conhecimento). Rio de Janeiro: Campus.

Szulanski, G. (2000). The process of knowledge transfer: A diachronic analysis of Stickness. Organizational Behavior and Human Decision Processes, 82(1), 9-27.

Thomke, S., \& Reinertsen, D. (1998). Agile product development: Managing development flexibility in uncertain environments. California Management Review, 41(1), 8-30.

Tilly, C. O. (2006). Unequal access to scientific knowledge (Acesso desigual ao conhecimento científico). Retrieved from http://dx.doi.org/10.1590/S0103-20702006000200003

Zhang, D., \& Zhao, J. L. (2006). Knowledge management in organizations. Journal of Database Management, 17(1), 1-15. 